\title{
INVESTIGAÇÃO EPIDEMIOLÓGICA DE CASOS DE FEBRE AMARELA NA REGIÃO NOROESTE DO ESTADO DE SÃO PAULO, BRASIL
}

Teresinha Lisieux M. Coimbra*

Lygia Busch Iversson**

Marlene Spir*

Venâncio A. Ferreira Alves*

Marcos Boulos***

COIMBRA, T.L.M. et al. Investigação epidemiológica de casos de febre amarela na região noroeste do Estado de São Paulo, Brasil. Rev. Saúde públ., S. Paulo, 21:193-9, 1987.

RESUMO: Descreve-se investigação epidemiológica conduzida a partir da notificação de três casos suspeitos de febre amarela em moradores da região noroeste do Estado de São Paulo, Brasil, onde se identificou a presença de Aedes aegypti. Concluiu-se que se tratavam de casos de febre amarela silvestre adquirida em área endêmica do Estado vizinho de Mato Grosso. Apesar da presença de focos de Aedes aegypti nos locais de residência dos doentes, não foram encontradas evidências de transmissão do vírus amarílico nesses locais. O teste MAC ELISA mostrou-se de grande utilidade no rápido esclarecimento diagnóstico dos casos suspeitos da moléstia, ao lado das técnicas tradicionais, e no inquérito sorológico conduzido entre familiares, vizinhos e colegas de trabalho dos doentes.

UNITERMOS: Febre amarela, incidência. Aedes aegypti. Vigilância epidemiológica.

\section{INTRODUÇÃO}

Na última semana de maio de 1985 as autoridades sanitárias foram notificadas da suspeita de febre amarela em dois moradores da área urbana de Presidente Prudente e um morador da área rural de Santo Expedito, municípios da região noroeste do Estado de São Paulo, o primeiro situado a $22^{\circ} 7^{\prime} \mathrm{S}$ e $51^{\circ} 27^{\prime} \mathrm{W}$, distante 515 $\mathrm{Km}$ em linha reta da cidade de São Paulo e o segundo, vizinho ao primeiro a $21^{\circ} 51^{\prime} \mathrm{S} 51^{\circ} 28^{\prime} \mathrm{W}$ (Figura 1). Suspeitou-se da moléstia após o óbito do primeiro caso, um adulto do sexo masculino, que havia recentemente viajado para o Estado do Mato Grosso, área endêmica de febre amarela silvestre.

O fato mobilizou, rapidamente, a Superintendência de Campanhas de Saúde Pública (SUCAM) do Ministério da Saúde, a Superintendência de Controle de Endemias (SUCEN) e o Instituto Adolfo Lutz, da Secretaria de Estado da Saúde de São Paulo, pois desde 1942 não se registrava a doença em sua forma urbana no país, e desde 1953 não se tinha conhecimento da ocorrência de casos de febre amarela no Estado de São Paulo.

A identificação em Presidente Prudente de 44 focos larvários de Aedes aegypti, clássico transmissor urbano da doença, propiciava o risco de uma epidemia. Em abril de 1977 os dois municípios, Presidente Prudente e Santo Expedito, haviam sido alvo de vacinação maciça contra febre amarela; no primeiro foram vacinados $59.289 \mathrm{de}$
125.269 habitantes das áreas urbana e rural e no segundo 1.927 de 2.215 habitantes****. Mas a migração e o crescimento vegetativo da população nas duas localidades aumentaram, nesses 8 anos, o componente de população não imunizada.

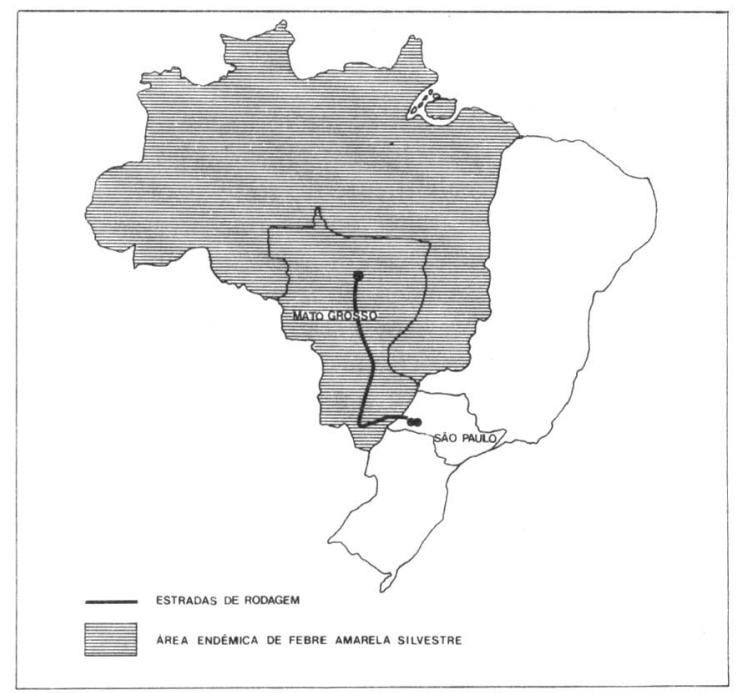

Fig. - Localização dos municípios de Presidente Prudente e São Expedito no Estado de São Paulo e Sinop no Estado de Mato Grosso.

* Instituto Adolfo Lutz da Secretaria de Estado da Saúde de São Paulo - Av. Dr. Arnaldo, 355 - 01246 - São Paulo, SP - Brasil.

** Departamento de Epidemiologia da Faculdade de Saúde Pública da Universidade de São Paulo - Av. Dr. Arnaldo, 715 01255 - São Paulo, SP - Brasil.

*** Superintendência de Controle de Endemias (SUCEN) da Secretaria de Estado da Saúde de São Paulo - Rua Paula Souza, 166 - 01027 - São Paulo, SP - Brasil; e Clínica de Doenças Infecciosas e Parasitárias do Hospital das Clínicas da Faculdade de Medicina da Universidade de São Paulo - Av. Dr. Enéas de Carvalho Aguiar, 255 - 05403 - São Paulo, SP - Brasil.

**** Informação obtida nos registros da SUCAM - Regional de São Paulo. 
Além de providências imediatas de eliminação dos focos de $A e$. aegypti, urgia a rápida confirmação do diagnóstico dos casos suspeitos, o esclarecimento de caráter autóctone ou alóctone da infecção humana, a busca de novos casos e a verificação de possível existência de vetor urbano infectado. Este trabalho tem por objetivo o relato seqüencial das medidas tomadas nesse sentido.

\section{MATERIAL E MÉTODOS}

Desenvolveram-se as seguintes atividades nas diferentes etapas da investigação epidemiológica:

\section{Confirmação do diagnóstico clínico}

Para pesquisa de anticorpos do vírus da febre amarela examinaram-se amostras de soro dos três pacientes utilizando-se os testes de fixação de complemento (FC), inibição de hemaglutinação (IH) e teste imunoenzimático com captura de anticorpo IgM (MAC ELISA). Em um dos pacientes efetuou-se teste de neutralização em camundongo. De apenas um doente foi possível a coleta de amostras pares de soro com intervalo de 10 dias. Os outros dois pacientes evoluíram para óbito no sétimo e oitavo dias da doença, dispondo-se de amostras de sangue obtidas no $4^{\circ}$. dia de um deles e nos terceiro, quinto e sexto dias do outro.

Os testes de fixação de complemento e de neutralização foram realizados com técnica descrita por Casals ${ }^{2}$ (1967); o de inibição de hemaglutinação segundo procedimentos de Shope $^{10}$ (1963), usando 4 unidades dos antígenos de febre amarela (YF), Rocio (ROC), Ilheus (ILH), encefalite de St. Louis (SLE) e dengue tipo I (DEN 1).

Em MAC ELISA usou-se microplacas de poliestireno Immulon II Dynatech, sensibilizadas com anti-IgM humana. No desenvolvimento do teste as placas foram incubadas a $37^{\circ} \mathrm{C}$ durante uma hora, sucessivamente, com os soros dos pacientes, na diluição $1 / 100$, com extratos antigênicos do vírus de febre amarela e Ilheus* previamente titulados, com o conjugado de fosfatase alcalina e anticorpo monoclonal de reatividade ampla para flavivírus, preparado contra o vírus SLE** (6 B6C-1).

Adicionou-se substrato de nitrofenil fosfato e a reação foi interrompida com HONa depois de $30 \mathrm{~min}$. Entre as diversas etapas, as lavagens das placas foram efetuadas com solução de PBS 0,05\% Tween ( $\mathrm{pH} 7,5$ ). A reação foi medida espectrofotometricamente $(410 \mathrm{~nm}) \mathrm{em}$ aparelho Minireader Dynatech. Controles de soros negativos, positivo, PBS e conjugados foram incluídos em todos os testes. A positividade do teste foi avaliada pela razão $\mathrm{P} / \mathrm{N}>2(\mathrm{P}=$ densidade ótica do soro testado na diluição $1 / 100$ e $\mathrm{N}=$ média das densidades óticas dos soros negativos controles na mesma diluição).

Em todos os casos se tentou o isolamento do vírus do sangue pela inoculação em camundongos recém-nas- cidos, de acordo com técnica descrita por Casals ${ }^{2}$ (1967). Dos dois doentes que faleceram coletou-se material para exame anatomopatológico de fígado e tentativa de isolamento de vírus dessa víscera.

Para este último procedimento efetuou-se suspensão de fígado a $10 \%$ em albumina bovina, fração $\mathrm{V}$, em solução a $0,75 \%$ de fosfato salina $0,05 \mathrm{M}, \mathrm{pH} 7,2$ contendo $100 \mu$ de penicilina e $100 \mathrm{mg}$ de estreptomicina. Depois de centrifugada por $10 \mathrm{~min}$ à temperatura de $-6^{\circ}$, o sobrenadante foi inoculado por via intracerebral em dois leitos de camundongos albinos recém-nascidos, $0,02 \mathrm{ml}$ por animal. No oitavo dia de inoculação foram feitas duas passagens sucessivas de suspensão de cérebro dos camundongos que não haviam apresentado sinais que indicassem a presença do vírus. No nono dia após a segunda passagem observou-se em alguns animais paralisia e letargia. A suspensão de cérebro dos animais foi reinoculada, após filtração, em três leitos dos camundongos. A identificação do vírus isolado dos animais doentes foi efetuada por teste de fixação de complemento, utilizando-se soros imunes dos vírus de YF, ROC, SLE, ILH e DEN-1.

Os testes de FC, $\mathrm{HI}$, as tentativas de isolamento de vírus do sangue e fígado e o exame anatomopatológico desta víscera foram realizados no Instituto Adolfo Lutz, Secretaria de Estado da Saúde de São Paulo; o teste de neutralização em camondongo no Instituto Evandro Chagas, Ministério de Saúde e MAC ELISA no Departamento de Epidemiologia, Faculdade de Saúde Pública da Universidade de São Paulo.

\section{RESULTADOS}

\section{Determinação do caráter autóctone ou alóctone das in- fecções}

Foram levantados dados referentes às atividades e locais freqüentados pelos doentes nos 7 dias anteriores ao aparecimento dos primeiros sintomas, tendo em vista o conhecimento sobre o período máximo de incubação da moléstia.

\section{Busca de possíveis novos casos}

Procurou-se esclarecer o diagnóstico, com apoio laboratorial (testes FC, IH e MAC ELISA), dos 18 casos com suspeita clínica de febre amarela, notificados em Presidente Prudente e em outros municípios próximos. Em cinco desses casos os sintomas (febre, mialgia, cefaléia intensa e, às vezes, náuseas) surgiram 5 a 13 dias após a vacinação contra febre amarela efetuada na área, quando da notificação dos 3 casos.

Com a finalidade de verificar a presença de infecções subclínicas, realizou-se inquérito sorológico em 97 pessoas, onde se incluíram 10 familiares, 82 vizinhos e 5 companheiros de trabalho dos doentes (caminhoneiros que costumam viajar para outros Estados). Os soros fo-

* Os antígenos foram obtidos da coleção de referência da "Division of Vector-Borne Viral Diseases. Centers for Disease Control" - EUA.

** Cedido pelo Dr. John Roehring da "Divison of Vector-Borne Viral Diseases. Centers for Disease Control" - EUA. 
TABELA 1

Resultados dos testes sorológiocos realizados em três casos suspeitos de febre amarela, moradores da região noroeste do Estado de São Paulo, 1985.

\begin{tabular}{|c|c|c|c|c|c|c|c|c|c|c|c|c|c|c|c|c|}
\hline \multirow[t]{2}{*}{ Paciente } & \multirow{2}{*}{$\begin{array}{l}\text { Coleta de soro - } \\
\text { dias após início } \\
\text { dos sintomas }\end{array}$} & \multicolumn{5}{|c|}{$\mathrm{IH}^{*}$} & \multicolumn{5}{|c|}{$\mathrm{FC}^{*}$} & \multicolumn{2}{|c|}{ MAC ELISA** } & \multicolumn{3}{|c|}{$\begin{array}{l}\text { Neutralização em } \\
\text { camundongo*** }\end{array}$} \\
\hline & & $\mathrm{YF}$ & ROC & SLE & ILH & DEN 1 & YF & ROC & SLE & ILH & DEN 1 & YF & ILH & YF & SLE & ILH \\
\hline C.A.R. & 4 & 20 & 10 & $<10$ & $<10$ & $<10$ & NT & NT & NT & NT & NT & $<2$ & $<2$ & NT & NT & NT \\
\hline \multirow[t]{2}{*}{ H.P.F. } & 6 & 160 & 20 & 20 & 40 & 20 & NT & NT & NT & NT & NT & 3.9 & 2.1 & NT & NT & NT \\
\hline & 16 & 160 & 20 & 20 & 40 & 20 & 32 & 8 & 16 & 16 & 8 & 4.9 & 2.5 & 3.7 & $\leq 0.8$ & $\leq 1.1$ \\
\hline \multirow[t]{2}{*}{ J.C.B. } & 3 & $<10$ & $<10$ & $<10$ & $<10$ & $<10$ & NT & NT & NT & NT & NT & $<2$ & $<2$ & NT & NT & NT \\
\hline & 6 & 20 & $<10$ & $<10$ & $<10$ & $<10$ & $<10$ & $<10$ & $<10$ & $<10$ & $<10$ & 2.8 & $<2$ & NT & NT & NT \\
\hline
\end{tabular}

* Reciproca da diluição do soro

** $\quad$ DO do soro testado

média do DO dos controles negativos

*** log. índice de neutralização

$\mathrm{NT}=$ Não testado

ram testados inicialmente para $\mathrm{IH}$. Os soros positivos foram testados para FC e MAC ELISA (Tabela 1).

\section{Possivel presença de vetor urbano infectado}

Dois dias antes da aplicação de inseticida em Presidente Prudente, duas equipes, de três pessoas cada procederam à coleta de larvas e à captura de formas adultas do Aedes aegypti em locais considerados de risco, ou seja, vizinhanças dos dois hospitais onde foram internados os doentes, suas residências, duas borracharias e um depósito de ferro velho. As equipes trabalharam nove horas diárias no período diurno ( 8 às 12 e 13 às 18). Os mosquitos, capturados por aspiração, foram mantidos em nitrogênio líquido até serem transferidos para freezer a $-60^{\circ} \mathrm{C}$ no laboratório, onde foram identificados, separados em dois lotes e inoculados em camundongos recém-nascidos.

Confirmação diagnóstica dos três casos suspeitos e verificação do local da infeç̧ão

Relato dos casos:

C.A.R. - Em 17/5 apresentou febre, calafrios e dor muscular. Medicou-se com analgésico e ingeriu bebida alcoólica (era alcoólatra crônico, segundo depoimento dos que o conheciam). Em 19/5 apresentou um progressivo agravamento dos sintomas com o aparecimento de dores articulares, lombares e abdominais. Em 21/5 teve início um quadro diarréico (com eliminação de sangue), observando-se a seguir o aparecimento de ictericia, tendo sido internado nesse dia com diagnóstico de hepatite. O óbito ocorreu no dia $24 / 5$ às 3 horas. C.A.R., que residia na zona urbana de Presidente Prudente, trabalhava como caminhoneiro para uma indústria de bebidas que, periodicamente, faz transportes para outros Estados. Em 4/5 partiu de Presidente Prudente com destino a Sinop e Marcelândia, no Estado de Mato Gros- so. Permaneceu nesses locais entre os dias $7 / 5$ à noite e $18 / 5$ pela manhã, tendo estado em contato com ambiente florestal onde estava havendo derrubada de mata. Em 18/5 iniciou o retorno para Presidente Prudente, já com os primeiros sintomas de doença, tendo chegado a esta cidade em $20 / 5$, à noite. C.A.R. apresentou quadro clínico e antecedente epidemiológico presuntivo da moléstia e um exame anatomopatológico de fígado sugestivo, conforme dados constantes da Tabela 2 .

H.P.F. - Durante três dias, a partir de $18 / 5$, teve febre e calafrios. Medicou-se com aspirina e vitaminas. No quarto dia regrediram esses sintomas, voltando às atividades normais. A suspeita de febre amarela foi aventada depois do falecimento de C.A.R., com quem havia viajado para o Estado de Mato Grosso no período de $4 / 5$ a $20 / 5$, pois trabalhava para a mesma indústria de bebidas. $O$ diagnośtico presuntivo da doença foi possível pelo encontro no soro do doente de anticorpos IgM para febre amarela e pela presença de anticorpos neutralizantes, reação monotípica para esse vírus (Tabela 1).

J.G.B. - Os primeiros sintomas, febre, cefaléia, mialgia, artralgia e vômitos, fizeram-se presentes em $24 / 5$. Em 26/5 apresentou urina escura e vômitos com aspecto de borra de café. No dia seguinte, ictericia, tendo sido internado inicialmente em hospital de Presidente Prudente com suspeita de febre amarela. Foi removido para São Paulo em 29/5 onde recebeu cuidados de terapia intensiva. $\mathrm{O}$ óbito ocorreu em 1/6. O pacierre desenvolveu quadro de insuficiência renal, miocardite, pneumonite, quadro hemorrágico difuso e choque precedendo o óbito. Em 18/5 havia viajado para uma fazenda no Muninípio de Sinop onde permaneceu de 19 a 22/5. No local teve contato direto com mata onde estava ocorrendo extração de madeira. Apresentou os primeiros sintomas em $24 / 5$, durante viagem de regresso ao Município de Santo Expedito, local de residência, onde chegou em 26/5. O diagnóstico de febre amarela (Tabelas 
TABELA 2

Exame anatomopatológico e tentativa de isolamento de vírus de febre amarela de moradores da região noroeste do Estado de São Paulo, 1985

\begin{tabular}{|c|c|c|c|c|}
\hline \multirow{2}{*}{ Paciente } & \multirow{2}{*}{$\begin{array}{l}\text { Evolução } \\
\text { Clínica }\end{array}$} & \multicolumn{2}{|c|}{ Isolamenio de vírus } & \multirow{2}{*}{ Exame anatomopatológico do fígado } \\
\hline & & sangue & fígado & \\
\hline \multirow{3}{*}{ C.A.R. } & \multirow{3}{*}{$\begin{array}{l}\text { óbito no } \\
77^{\circ} \text { dia de } \\
\text { doença }\end{array}$} & $\longmapsto$ & \multirow[t]{3}{*}{$\mapsto$} & \multirow{3}{*}{$\begin{array}{l}\text { alterações hepáticas sugestivas de } \\
\text { infecção por vírus da febre amarela ou } \\
\text { hepatites } \mathrm{A} \text { e } \mathrm{B}^{*}\end{array}$} \\
\hline & & (4) & & \\
\hline & & $\mapsto$ & & \\
\hline H.P.F. & cura & (6) & NR & NR \\
\hline J.G.B & $\begin{array}{l}\text { óbito no } \\
8 .^{\circ} \text { dia de } \\
\text { doença }\end{array}$ & $\rightarrow$ & + & $\begin{array}{l}\text { alterações hepáticas próprias de infecção } \\
\text { recente pelo vírus da febre amarela. }\end{array}$ \\
\hline
\end{tabular}

$\mathrm{NR}=$ Não realizado

( ) = Dias após início dos sintomas da coleta de soro

* Arquitetura hepática distorcida, observando-se traves de colágeno tipo I delimitando nódulos irregulares com hapatócitos de volume aumentado, com esteatose macro e microgoticular. São exuberantes as figuras de necrose, especialmente mediozonal, mas, também, centrilobular e até periférica, em geral poupando algumas camadas de hepatócitos junto aos septos. São muito freqüentes os corpos hialinos de Councilmann - Rocha Lima. O infiltrado inflamatório é constituído por linfócitos, além de alguns macrófagos, plasmócitos e raros polimorfonucleares. O colapso do retículo, formando-se septos de colágeno III, também é bastante evidente. Raros macrófagos contêm pigmento férrico, mas diversos hepatócitos centrilobulares e mediozonais contêm pigmento acastanhado (ceróide).

Conclusão: Os achados são de necrose hepática submaciça recente, assentada sobre cirrose pré-existente.

1 e 2) foi confirmado por sorologia, exame anatomopatológico e isolamento de vírus do fígado.

O primeiro exame laboratorial com resultado presuntivo de febre amarela foi MAC ELISA em 30/5/85 que identificou anticorpos IgM de febre amarela na primeira amostra de sangue do paciente H.P.F. A identificação dos mesmos anticorpos IgM de febre amarela na segunda amostra de soro do doente J.G.B. também antecipou os resultados positivos do exame anatomopa- tológico e da tentativa de isolamento de vírus amarílico do fígado desse paciente.

O caráter não autóctone da infecção nos 3 doentes foi claramente estabelecido por informações da anamnese clínica.

\section{Busca de outros casos}

Os resultados dos testes sorológicos com antígenos de

\section{TABELA 3}

Resultados dos exames de laboratório em três das 18 pessoas doentes investigadas, moradores da região noroeste do Estado de São Paulo, 1985.

\begin{tabular}{lcrrcc}
\hline Doente & $\begin{array}{c}\text { Data da coleta } \\
\text { do sangue }\end{array}$ & \multicolumn{2}{c}{ Testes com antígeno de YF } & Isolamento de vírus de YF \\
& $15 / 06 / 85$ & 160 & $<8$ & $<2$ & do sangue \\
\hline L.A.S.*** & $04 / 07 / 85$ & 160 & $<8$ & NR & MAC ELISA** \\
& $26 / 06 / 85$ & $<10$ & 8 & $<2$ & + \\
R.R.*** & $28 / 10 / 85$ & $<10$ & 8 & NR & NR \\
& $24 / 05 / 85$ & 10 & $<8$ & $<2$ & N \\
A.J.A. & & &
\end{tabular}

* Recíproca da diluição do soro

** DO do soro testado

Média de DO dos controles negativos

*** Vacinação recente contra febre amarela

NR: Não realizado 
TABELA 4

Soros com anticorpos para febre amarela entre as 97 pessoas sadias investigadas, moradores da região noroeste do Estado de São Paulo, 1985.

\begin{tabular}{|c|c|c|c|c|c|c|c|c|}
\hline \multirow{2}{*}{ Nome } & \multirow{2}{*}{$\begin{array}{l}\text { Relação com } \\
\text { os doentes }\end{array}$} & \multirow{2}{*}{$\begin{array}{c}\text { Idade } \\
\text { em anos }\end{array}$} & \multirow{2}{*}{ Sexo } & \multirow{2}{*}{$\begin{array}{c}\text { Data de coleta } \\
\text { do sangue }\end{array}$} & \multicolumn{4}{|c|}{ Resultado } \\
\hline & & & & & $\mathrm{IH}^{* *}$ & $\mathrm{FC}^{* *}$ & MAC & ELISA** $^{* *}$ \\
\hline A.L.R.L. & $\begin{array}{l}\text { vizinha de } \\
\text { H.P.F. }\end{array}$ & 28 & $\mathrm{~F}$ & $\begin{array}{l}30 / 05 \\
11 / 07\end{array}$ & $\begin{array}{l}40 \\
40\end{array}$ & $\begin{array}{l}8 \\
8\end{array}$ & & $<2$ \\
\hline O.E. & $\begin{array}{c}\text { colega de } \\
\text { trabalho de } \\
\text { H.P.F* }\end{array}$ & 43 & M & $\begin{array}{l}30 / 05 \\
10 / 07\end{array}$ & $\begin{array}{l}20 \\
40\end{array}$ & $\begin{array}{l}8 \\
8\end{array}$ & & $<2$ \\
\hline J.V.S. & $\begin{array}{c}\text { sogro de } \\
\text { J.G.B. }\end{array}$ & 50 & M & $\begin{array}{l}30 / 05 \\
05 / 07\end{array}$ & $\begin{array}{l}40 \\
80\end{array}$ & $\begin{array}{l}8 \\
8\end{array}$ & & $<2$ \\
\hline S.M.V.B. & $\begin{array}{c}\text { esposa de } \\
\text { J.G.B.* }\end{array}$ & 17 & F & $\begin{array}{l}30 / 05 \\
05 / 07\end{array}$ & $\begin{array}{l}20 \\
20\end{array}$ & $\begin{array}{l}8 \\
8\end{array}$ & & $<2$ \\
\hline M.S.A. & $\begin{array}{l}\text { vizinha de } \\
\text { J.G.B. }\end{array}$ & 35 & $\mathrm{~F}$ & $\begin{array}{l}30 / 05 \\
05 / 07\end{array}$ & $\begin{array}{l}20 \\
20\end{array}$ & $\begin{array}{l}<8 \\
<8\end{array}$ & & $<2$ \\
\hline M.P.M. & $\begin{array}{l}\text { vizinho de } \\
\text { J.G.B. }\end{array}$ & 30 & M & $\begin{array}{l}31 / 05 \\
05 / 07\end{array}$ & $\begin{array}{l}20 \\
20\end{array}$ & $\begin{array}{l}8 \\
8\end{array}$ & & $<2$ \\
\hline A.R. & $\begin{array}{c}\text { vizinho de } \\
\text { J.G.B.* }\end{array}$ & 50 & M & $\begin{array}{l}01 / 06 \\
05 / 07\end{array}$ & $\begin{array}{l}40 \\
40\end{array}$ & $\begin{array}{l}8 \\
8\end{array}$ & & $<2$ \\
\hline J.R.L. & $\begin{array}{l}\text { vizinho de } \\
\text { J.G.B. }\end{array}$ & 35 & M & $\begin{array}{l}31 / 05 \\
05 / 07\end{array}$ & $\begin{array}{l}10 \\
10\end{array}$ & NT & & $<2$ \\
\hline
\end{tabular}

* Estiveram recentemente em área endêmica de febre amarela silvestre.

** Recíproca de diluição do soro

*** DO do soro testado

média de DO dos soros negativos

NT - Não testado

febre amarela, realizados em 18 casos suspeitos da moléstia, não confirmaram esse diagnóstico. Em dois dos doentes, com antecedente vacinal recente, observou-se a presença de anticorpos $\mathrm{FC}$ ou IH em título baixo, estável, em soros pares. Isolou-se o vírus vacinal do sangue de um deles. Um terceiro doente, sem antecedente vacinal, não residente em presidente Prudente em Santo Expedito, apresentou anticorpor IH em baixo título. $\mathrm{Na}$ única amostra de soro disponível MAC ELISA foi claramente negativo. (Tabela 3).

Os resultados do inquérito em familiares, vizinhos ou companheiros de trabalho dos doentes, expressos na Tabela 4, não indicam a presença de infecção recente por febre amarela nos investigados.

\section{Pesquisa de vetor infectado}

Foram capturados apenas 16 formas adultas do $A e$. aegypti, 6 nas proximidades dos hospitais e 10 em borracharias e no depósito de ferro velho de Presidente Prudente. Embora o período de captura de Ae. aegypti tivesse sido limitado pela urgência na aplicação do inseticida, observou-se número reduzido de formas aladas, apesar da identificação de numerosos focos larvários do mosquito.

Não se detectou o vírus da febre amarela nesses poucos exemplares da Ae.aegypti capturados.

\section{DISCUSSÃO}

A intensa comunicação rodoviária, ferroviária e aérea entre São Paulo e Estados da região centro-oeste (Mato Grosso do Sul, Mato Grosso e Goiás), áreas onde circula o vírus da febre amarela em ambiente silvestre, faz supor alto risco para a doença em viajantes, eventuais ou periódicos, que mantenham contacto com as áreas florestais desses locais.

Recentemente a equipe de virologistas do Instituto Evandro Chagas isolou o vírus da febre amarela de mosquitos do gênero Haemagogus, capturados no Município de Sinop*. A mencionada permanência dos três doentes no ambiente florestal de Sinop onde está ocorrendo derrubada de mata, esclarece o provável local da infecção e evidencia ocorrência de moléstia, prevenível por vacinação, em pessoas que apresentam um nítido risco profissional de adquirí-la. Independentemente da presença de vetor urbano no Estado de São Paulo, criando condições para a urbanização da moléstia, há urgência em orientar em relação à profilaxia da doença a população que se desloca para áreas endêmicas de febre amarela silvestre.

Considerando dados de 1985 do Censo de Tráfego do Departamento de Estradas de Rodagem de São Paulo (DNER) ${ }^{3}$, era de 6.372 veículos, entre ônibus, carros de passeio e caminhões, o volume médio diário de trá-

\footnotetext{
* Informação verbal da Dra. Amélia Travassos da Rosa e Dr. Jean Pierre Hervé, pequisadores da Seção de Arbovirus do Instituto Evandro Chagas.
} 
fego da rodovia estadual que de Presidente Prudente dá acesso para o sul matogrossense. Esse volume configura a intensa movimentação humana entre São Paulo e Estados da Região centro-oeste. Nessa população se incluem aqueles que periodicamente mantém contacto com o ambiente silvestre, quer por atividade profissional, quer por lazer, e que deveriam estar informados dos meios profiláticos disponíveis para moléstias cujo foco natural se situa nesse ambiente. Em algumas situações, tem-se verificado condenável resistência de lideranças desses locais quanto à divulgação de informações relativas ao risco de moléstias infecciosas, pelo temor do arrefecimento dos interesses turísticos e econômicos da área.

Considerando os dados disponíveis, não ocorreu urbanização da moléstia em Presidente Prudente. O número de exemplares de Ae.aegypti, capturados antes da aplicação do inseticida e em que se pesquisou o vírus amarílico, foi muito limitado para uma conclusão, mas os resultados dos testes sorológicos em investigados, doentes ou sadios, levam à suposição que se trata de uma ocorrência circunscrita aos homens que, sem proteção vacinal, haviam se deslocado à área endêmica.

MAC ELISA, tal como já descrito ${ }^{4.6,79}$, mostrou-se um teste sensível e valioso para o diagnóstico rápido, antecipando os resultados de técnicas tradicionais. A presença de anticorpos IgM nas arboviroses tem sido detectada por este teste nos primeiros 8 dias após o início dos sintomas, mais comumente a partir do quarto dia. No caso presente, resultados positivos foram observados em soros coletados após o sexto dia de moléstia em H.P.F. e J.G.B., pelo menos 7 dias antes que fosse possível uma confirmação diagnóstica por outras técnicas. A negatividade do teste de C.A.R., com amostra de sangue coletada no quarto dia de moléstia, não invalida o diagnóstico de febre amarela, apoiado em critério clínico-epidemiológico. A técnica tornou-se útil também, para rápido esclarecimento, confirmado a seguir por testes tradicionais, da não presença de casos secundários da moléstia conseqüente da possível transmissão urbana do vírus, reforçando as recomendações do Seminário Internacional sobre Diagnóstico e Tratamento de Febre Amarela, realizado em Brasília, em abril de 1984, que preconizou, entre outros ítens, o apoio institucio- nal na implantação de técnicas de diagnóstico rápido em áreas de risco de febre amarela.

A insucesso em recuperar o vírus do sangue dos três pacientes pode ser explicada pela coleta de amostrar em fase não virêmica. A presença de vírus no sangue circulante depois de 3 dias de moléstia, até o décimo segundo dia, já foi descrita' mas não é o comumente observado. Cumpre assinalar que nos 3 primeiros dias da doença os 3 pacientes estavam viajando de Mato Grosso a São Paulo. Assim, se ocorreu em São Paulo o contato desses homens com o Ae.aegypti, o foi em fase de provável menor potencial de transmissão da infecção.

A sintomatologia apresentada por vacinados após 5 a 13 dias é descrita em 2 a $10 \%$ dos vacinados com a vacina $17 \mathrm{D}^{5,11}$. Essas reações, em geral sem gravidade, durando de horas a 1 ou 2 dias, são confundidas com sintomas da própria doença em áreas onde estão ocorrendo casos, como a situação presente. A utilização do teste FC para diferenciar reação vacinal de infecção natural, baseada nas observações de ausência de anticorpos FC na reação vacinal, foi discutida em pesquisa recente conduzida em Gambia, África, quando essa ausência esteve presente só em primovacinados sem experiência imunológica prévia com flavivírus ${ }^{8}$. No caso presente não se pode excluir a presença de infecções prévias por outros flavivírus no paciente com reação vacinal que apresentou anticorpor FC. O isolamento de vírus vacinal em sangue circulante nesse paciente não se constitui fato incomum. Há observações de isolamento até o décimo dia após a vacinação".

\section{AGRADECIMENTOS}

À Dra. Amélia Travasso da Rosa, do Instituto Evanđro Chagas, Pará, pela colaboração na realização de teste de neutralização em soro de um dos pacientes e pela valiosa revisão do manuscrito; ao Dr. Oscar Souza Lopes, da Fundação Oswaldo Cruz, pelas valiosas sugestões; ao apoio técnico no laboratório e no campo prestado por: Adélia H. Nagamori, Akemi Suzuki, Carlos Roberto Elias, Dulce Maria de Souza, Elza Keiko Kimura, Elza da Silva Nassar, Ivani B. Ferreira, Luiz Eloy Pereira e Rui Larosa. 
COIMBRA, T.L.M. et al. [Epidemiological investigation into cases of yellow fever in the North- west region of S. Paulo State, Brazil]. Rev. Saúde públ., S. Paulo, 21, 193-9, 1987.

ABSTRACT: An epidemiological investigation was carried out in the North-west region of the State of S. Paulo of Brazil with the purpose of clarifying three suspected cases of yellow fever that occurred in people resident in the area. In this region the presence of Aedes aegypti had been verified. It was concluded that the patients had contrated yellow fever during a trip to the forested region of the Mato Grosso State, where there are enzootic cycles of the virus. Despite of the presence of Ae. aegypti, no evidence of yellow fever transmission in the local population was detected. MAC ELISA (enzyme-linked immunosorbent assay with capture of IgM antibodies) proved very useful in the rapid diagnosis of suspected cases and in the serological investigation among the relatives, neighbors and schoolmates of the patients, providing additional support for the traditional techniques.

UNITERMS: Yellow fever, occurrence. Aedes aegypti. Epidemiologic surveillance.

\section{REFERÊNCIAS BIBLIOGRÁFICAS}

1. BENSABATH, G.; PINHEIRO, F.P.; ANDRADE, A.H.P.; WOODALL, J.P. Excepcional achado em um caso humano de febre amarela. Isolamento de vírus a partir do sangue no $12^{\circ}$ dia de doença. Rev. Serv. esp. Saúde públ., 13(1): 95-104, 1967.

2. CASALS, J. Immunological techniques for animal viruses. In: Maramorosh, K. \& Koprowski, H. Methods in virology. New York, Academic Press, 1967. v. 3, p. 175-81.

3. DEPARTAMENTO DE ESTRADAS DE RODAGEM DO ESTADO DE SÃO PAULO. Estatistica de trânsito. AltE11 relativa ao ano de 1985. São Paulo, 1986.

4. DEUBEL, V.; MOULY, V.; SALAUN, J.J.; ADAM, C.; DIOP, M.M.; DIGOUTTE, J.P. Comparison of the enzyme-linked immunosorbent assay (ELISA) with standard tests used to detect yellow fever virus antibodies. Amer. J. trop. Med. Hyg., 32: 565-8, 1983.

5. IMMUNIZATION PRACTICES ADVISORY COMMITTEE. Yellow fever vaccine. Morb. Mort. Wkly Rep., 32(52): 679-88, 1984.

6. LHUILLIER, M. \& SARTHOU, J.L. Diagnostic immunologique rapide de la fièvre jaune: détection des IgM antiamariles devant une hépatite ictérigène contractée en milieu tropical. Presse méd., 12(29): 1822, 1983.
7. LHUILLIER, M. \& SARTHOU, J.L. Intérêt des IgM antiamariles dans le diagnostic et la surveillance épidémiologique de la fièvre jaune. Ann. Virol., 134E: 349-59, 1983.

8. MONATH, T.P.; CRAVEN, R.B.; MUTH, D.J.; TRAUTT, C.J.; CALISHER, C.H.; FITZGERALD, S.A. Limitations of the complement-fixation test for distinguishing naturally acquired from vaccine-induced yellow fever infection in flavivirus-hyperendemic areas. Amer. J. trop. Med. Hyg., 29: 624-34, 1980.

9. MONATH, T.P. \& NYSTROM, R.R. Detection of yellow fever virus in serum by enzyme immunoassay. Amer. $J$. trop. Med. Hyg., 33: 151-7, 1984.

10. SHOPE, R.E. The use of micro-hemagglutination - inhibition test to follow antibody response after arthropodborne virus infection in a community of forest animals. An. Microbiol., 11: 167-71, 1983.

11. STRODE, G., ed. Yellow fever. New York, Mc Graw Hill, 1951.

Recebido para publicação em 16/10/1986 Aprovado para publicação em 10/03/1987 